\section{Re: Cervical Spondylotic Myelopathy: A Guide to Diagnosis and Management}

To the Editor: We read with great interest the manuscript by McCormick and colleagues, ${ }^{1}$ "Cervical Spondylotic Myelopathy: A Guide to Diagnosis and Management."

First of all, we would like to congratulate the authors for the excellent review of the topic, allowing resident physicians and specialists to update us in an increasingly frequent pathology.

We agree with $\mathrm{Lo}^{2}$ in stating that electrophysiological studies are not routinely used to diagnose cervical myelopathy but may be of use to rule out other conditions, including carpal tunnel syndrome, multiple sclerosis, amyotrophic lateral sclerosis, subacute combined degeneration, or other neurologic diseases that demonstrate characteristic electromyographic patterns. The literature on this subject is inconsistent secondary to cost, availability, and the use of multiple modalities, such as motorevoked potentials, somatosensory-evoked potentials, nerve conduction studies, electromyography, and intraoperative monitoring.

Electrophysiology may play isolated roles in diagnosis, follow-up, and treatment. These disorders may present with predominantly myelopathic a careful neurologic examination and a thoughtful diagnostic evaluation are necessary to establish a diagnosis. ${ }^{3}$
As a single suggestion, we would like the authors to have complemented the assessment with a neurophysiological study with the electroneuromyography and, somatosensoryevoked potential.

We congratulate the authors for the report, and the opportunity to delve into a topic so interesting that it will serve as a motivation for further studies.

Otto J. Hernandez Fustes, MD, MSc Complexo Hospital de Clinicas-Universidade Federal do Paraná, Serviço de Neurologia, Serviço de Doenças Neuromusculares, Curitiba PR, Brasil otto.fustes@hc.ufpr.br

Carlos Arteaga Rodriguez, MD, MSc

To see this article online, please go to: http://jabfm.org/content/ 33/6/1033.full.

\section{References}

1. McCormick JR, Sama AJ, Schiller NC, Butler AJ, Donnally IIC. Cervical spondylotic myelopathy: a guide to diagnosis and management. J Am Board Fam Med 2020;33:303-13.

2. Lo YL. How has electrophysiology changed the management of cervical spondylotic myelopathy? Eur J Neurol 2008;15:781-6.

3. Goodman BP. Diagnostic approach to myeloneuropathy. Continuum (Minneap Minn) 2011;17:744-60.

doi: 10.3122/jabfm.2020.06.200317 